\title{
INFINITE REFINEMENTS OF THE DISCRETE JENSEN'S INEQUALITY DEFINED BY RECURSION
}

\section{LÁSZLÓ HORVÁTH}

Abstract. In this paper we give very general refinements of the discrete Jensen's inequality for convex and mid-convex functions defined by recursion. Conditions are given for strict inequality which is rare in this topic. In some cases explicit formulas are obtained. The results contain and generalize earlier statements. As an application we define some new quasi-arithmetic means and study their (strict) monotonicity.

Mathematics subject classification (2010): 26D15.

Keywords and phrases: Discrete Jensen's inequality; convex functions; recursion.

\section{REFERENCES}

[1] G. H. Hardy, J. E. Littlewood, G. Pólya, Inequalities, Cambridge Mathematical Library Series, 1967, Cambridge University Press.

[2] L. Honváth, A parameter dependent refinement of the discrete Jensen's inequality for convex and mid-convex functions, J. Inequal. Appl. (2011) 2011:26, 14 pp.

[3] L. HoRvÁth, A new refinement of the discrete Jensen's inequality depending on parameters, J. Inequal. Appl. (2013) 2013:551, 16 pp.

[4] L. HoRVÁth, Weighted form of a recent refinement of the discrete Jensen's inequality, Math. Inequal. Appl. 17 (2014) No. 3, 947-961.

[5] L. Horváth, Khuram Ali Khan, J. PeČARIć, Combinatorial improvements of Jensen's inequality, Element, Zagreb, 2014.

[6] Z.-G. Xiao, H. M. SRivastava, Z.-H. Zhang, Further refinements of the Jensen inequalities based upon samples with repetitions, Math. Comput. Modelling 51 (2010) 592-600. 